\title{
Observatorio Sociocultural del Oeste de Montevideo: una plataforma integral universitaria
}

\author{
Socio-cultural Observatory of the West of Montevideo: An integral \\ university platform
}

\author{
Miguel Olivetti Espina, Jorge Castro Falero, Guillermo Lago y Cecilia Rodríguez*
}

Fecha de recepción: 29-04-2017 - Fecha de aceptación: 09-08-2017

Hábitat y Sociedad (ISSN 2173-125X), n. ${ }^{\circ}$ 10, noviembre de 2017, pp. 145-162.

http://dx.doi.org/10.12795/HabitatySociedad.2017.i10.09

\begin{abstract}
A general description of the Social Observatory of the West of Montevideo is carried out together with an analysis of the main dimensions of the same and its implications, presenting the result of a research carried out within the framework of the Observatory on the discursive materialities related to the dimensions of inhabiting in the West of Montevideo, main task of this platform that aims to systematize and interpret the discursivities associated with the referred territories.

The description and analysis is structured taking into consideration the three axes from which the Observatory is developed: architecture, design and urban communication; Mass media and representations of the territory; Local media and representations of the territory. The methodologies and activities developed in the Observatory are carried out within the framework of the Integral Training Spaces of the University of the Republic, seeking to transform the quality of the participation of the inhabitants in the construction of the devices that configure their interactions with the habitat in The territories of the West of Montevideo.

The detection of processes of exclusion of this territory and its inhabitants in the media representations, as part of the results of the referred research, as well as the causes suggested by the same are approached carefully and enable a series of reflections that are exposed to Mode of exercise of visualization and problematization of the processes of social production of the habitat in the territories of the West of Montevideo
\end{abstract}

\section{Key words}

Habitat, Social Change, Territory, Exclusion, Citizen participation

\section{Resumen}

Se realiza una descripción general del Observatorio Sociocultural del Oeste de Montevideo conjuntamente a un análisis de las principales dimensiones del mismo y sus implicaciones, presentando el resultado de una investigación realizada en el marco del Observatorio sobre las materialidades discursivas vinculadas a las dimensiones del habitar en el Oeste de Montevideo, cometido principal de esta plataforma que persigue sistematizar e interpretar las discursividades asociadas a los territorios referidos.

La descripción y el análisis se estructura teniendo en consideración los tres ejes a partir de los cuales se desarrolla el Observatorio: arquitectura, diseño y comunicación urbana; medios masivos y las representaciones del territorio; medios locales y las representaciones del territorio. Las metodologías y actividades desarrolladas en el Observatorio se efectúan en el marco de los Espacios de Formación Integral de la Universidad de la República, ${ }^{1}$ buscando transformar la calidad de la participación de los habitantes en la construcción de los dispositivos que configuran sus interacciones con el hábitat en los territorios del Oeste de Montevideo.

La detección de procesos de exclusión de este territorio y sus habitantes en las representaciones mediáticas, como parte de los resultados de la investigación referida, así como las causas sugeridas por la misma, son abordados detenidamente y habilitan a una serie de reflexiones que son expuestas a modo de ejercicio de visualización y problematización de los procesos de producción social del hábitat en los territorios del Oeste de Montevideo.

\section{Palabras clave}

Hábitat; Transformación Social; Territorio; Exclusión; Participación ciudadana

\footnotetext{
* Miguel Olivetti Espina: licenciado y maestrando en Comunicación, prof. adjunto FADU-UdelaR y APEX-UdelaR. Facultad de Arquitectura, Diseño y Urbanismo, UdelaR. Bv. Gral. Artigas, 1031, CP 11200. C.e.: miolivetti@gmail.com. Jorge Castro Falero: sociólogo y maestrando en Educación, prof. adjunto FADU-UdelaR. Guillermo Lago: diseñador industrial, docente asistente FADU-UdelaR. Cecilia Rodríguez: licenciada en Trabajo Social, docente ayudante APEX- UdelaR.

1 Espacios de Formación Integral. Portal UdelaR. Recuperado el 25/04/2017 de http://www.ei.udelar.edu.uy/prensa/renderItem/itemId/36406.
} 


\section{Introducción}

El Observatorio Sociocultural del Oeste de Montevideo es una plataforma universitaria integral, que busca sistematizar e interpretar diferentes materialidades discursivas, vinculadas a las dimensiones del habitar en el Oeste de Montevideo. Como objetivo último se propone transformar la calidad de la participación de los habitantes en el diseño de los dispositivos que configuran sus formas de interacción con el hábitat en los territorios del Oeste de Montevideo. Es categorizado como "integral" porque contempla la articulación de las tres funciones universitarias, la extensión, la enseñanza y la investigación, también se configura desde el diálogo de saberes, tanto de actores universitarios como de actores no universitarios y además se constituye desde una concepción interdisciplinaria. Se constituye a partir de la concurrencia de tres servicios de la Universidad de la República de Uruguay (UdelaR), ellos son la Escuela Universitaria Centro de Diseño de la Facultad de Arquitectura, Diseño y Urbanismo (EUCD-FADU), la Facultad de Información y Comunicación (FIC) y el Programa Integral APEX, que tiene un anclaje territorial en el Municipio A de Montevideo, en la zona oeste. El Observatorio se estructura, en una primera etapa, a partir de tres ejes que atienden a la mirada sobre la vida cotidiana en este territorio. Los mismos son: 1) Arquitectura, diseño y comunicación urbana en los territorios del oeste de Montevideo, 2) Medios masivos y las representaciones del territorio y 3) Medios locales y las representaciones del territorio. Las actividades del Observatorio se configuran en el marco de Espacios de Formación Integral $(\mathrm{EFI})^{2}$ de diferentes niveles y características. Estos espacios son cursados por estudiantes de distintos servicios de la UdelaR en los que se trabaja, a partir de problemáticas sociales, en el intercambio con los sujetos que habitan en los territorios, siguiendo ciertas líneas de investigación propuestas por el equipo docente que es interdisciplinario.

En el Observatorio Sociocultural del Oeste de Montevideo, a través de los diferentes EFI, se generan espacios de intercambio permanente de estudiantes de diferentes disciplinas (comunicación, arquitectura, diseño, medicina, trabajo social, psicología, entre otros) con sus docentes referentes y con los habitantes del Oeste de Montevideo, con el objetivo de producir y seleccionar materialidades discursivas que pertenecen a diferentes sistemas semióticos y que permiten alimentar los repositorios documentales de cada uno de los ejes de trabajo (fotografías, audiovisuales, recortes de prensa, escritos, mapas, objetos, indumentarias, entre otros). Los Espacios de Formación Integral incluyen también etapas de análisis e interpretación de las materialidades construidas, que permiten ir explicando las dimensiones que constituyen el habitar cotidiano en los territorios del oeste de Montevideo. Se trabaja con herramientas de Análisis Crítico del Discurso desde una perspectiva socio-semiótica multimodal, en busca de conocer cómo son las expresiones objetuales, arquitectónicas, urbanísticas, mediáticas que configuran líneas ideológicas, relaciones de poder en el territorio, exclusiones e inclusiones de actores sociales. En definitiva, se analizan las formas de representación del territorio a partir de la convergencia de las diversas materialidades expresadas y cómo ellas intervienen en los procesos de construcción de las subjetividades en el propio territorio. Se evalúa que este proceso, que es realizado en conjunto con los propios habitantes, tiene un gran potencial transformador de los territorios. A través de una deconstrucción de las dimensiones que definen 
la vida cotidiana se apunta a una reconfiguración de las mismas, en un sentido que apunte a una mayor participación de los habitantes en los procesos definitorios de su vida.

\section{Descripción general del Observatorio. Actividades realizadas y herramientas teórico-metodológicas}

En el primer semestre de 2016 se realizó el primer EFI vinculado al Observatorio Sociocultural, coordinado entre FADU-EUCD y APEX. A partir de este EFI de sensibilización denominado "Pensar Diseño", estudiantes de primer año de la FADU-EUCD de la unidad curricular "Laboratorio de Funciones Universitarias Integradas y Equipos de Alto Rendimiento" realizaron su intervención curricular en el marco del Observatorio. Con el objetivo de identificar la diversidad simbólica de representar la vida cotidiana en el Cerro de Montevideo, a partir de edificación, monumentos, fotografía, arte pictórico, deportes etc., se trabajó con 12 grupos de 6 estudiantes cada uno en diferentes zonas del Cerro de Montevideo. De esta forma, 2 grupos trabajaron en Santa Catalina, 2 grupos en Casabó, 4 grupos en la Villa del Cerro en AJUPEN-FOICA (Asociación de Jubilados y Pensionistas de la Federación de la Industria de la Carne y Afines), 2 grupos en la Boyada en el complejo 19 de junio y 2 grupos en el Parque Tecnológico Industrial del Cerro. Se buscaba un proceso de integración de funciones universitarias, centradas en el intercambio de saberes y trabajo colaborativo entre los actores de la comunidad, los docentes y los estudiantes. A partir de este proceso se siguieron las pautas de selección que conllevan los procesos de producción de imagen. Se realizó en cada zona un intercambio con relación a las problemáticas de la vida cotidiana en el barrio que involucren espacios públicos, monumentos, etc., y dimensiones arquitectónicas. Se sugirió a los estudiantes estar atentos a las anécdotas, experiencias, rituales u otras expresiones con relación a estos espacios y arquitecturas, y cuáles son los significados que estos adquirían para las personas que participaban de la actividad. Se solicitó a los estudiantes, generar una planilla con algunas ideas para fotografiar que surgieran a partir de los diálogos establecidos.

Con el objetivo de identificar las formas de representación establecidas por la prensa masiva de Montevideo en relación al territorio y los habitantes del Cerro de Montevideo, se trabajó en la recolección y sistematización de artículos de prensa masiva digital que hiciesen referencia al Cerro de Montevideo, en alguna de las siguientes orientaciones de búsqueda que contuviesen la palabra Cerro, Cerro Norte, La Boyada, Santa Catalina, Casabó (territorios adyacentes al Cerro de Montevideo), entre otras. Se trabajó con 12 grupos de 6 estudiantes y a cada uno de ellos se le asignó un mes del año en curso y de 2015 para relevar, dentro de los medios más importantes propuestos por el equipo docente. El estudiante, además de relevar y sistematizar las noticias en el período asignado, debió tener una instancia de aproximación al barrio y a la comunidad, en relación a los avances obtenidos en su dinámica. Las mismas se realizan siguiendo una guía docente. La misma dinámica fue propuesta con relación a la prensa local. Esta sistematización fue realizada por 4 grupos de 6 estudiantes cada uno. Finalizando el primer semestre de 2016, los resultados fueron:

Se generó un repositorio digital con centenares de archivos de prensa masiva, prensa local, fotografías de arquitectura y urbanismo en el Ce- 
rro de Montevideo. Se instrumentó una metodología de construcción del repositorio basada en el diálogo de saberes, participando del Observatorio: estudiantes y docentes de EUCD- FADU, docentes de APEX, integrantes de organizaciones vecinales, sociales y productivas del Cerro de Montevideo (AJUPEN-FOICA, 19 de junio, PTI, SOCAT de IPRU, además de vecinos no organizados como Máximo Rodríguez y Odorico Velázquez). Se realizó una jornada de exposición de póster con resultados de cada grupo de estudiantes en la AJUPEN- FOICA y FADU.

La segunda etapa, que se inició en el segundo semestre de 2016, posibilitó una interpretación de los datos construidos en el primer semestre, con el acento puesto en las representaciones de la vida cotidiana en el Cerro de Montevideo en relación al mundo del trabajo, la vivienda, la inmigración, la salud, la seguridad pública, etc. Se trabajó en el marco del Espacio de Formación Integral: "Territorio, Diseño y Comunicación Urbana”. El curso se enmarca en las actividades del Observatorio Sociocultural del Oeste de Montevideo, en las que también participó el Laboratorio Transdisciplinario de Etnografía Experimental del Instituto de Comunicación (DCHS-IC-FIC). Fue un curso teórico-práctico y de carácter semestral, a partir de la integración de la investigación y la extensión. Se llevaron a cabo 15 sesiones de 3 horas cada una. Se trabajó en forma grupal interdisciplinaria, a partir de grupos de estudios conformados por integrantes de las diversas Facultades presentes en cada año lectivo junto a Comunicación, Diseño y estudiantes de Apex provenientes de Trabajo Social y Psicología. Los estudiantes realizaron: relevamientos exploratorios de corte etnográfico, análisis de documentación, fichas de lectura y trabajos finales de tipo escrito, visual y audiovisual, así como la combinación de las diversas modalidades. Las temáticas se abordaron a partir de actividades integrales (investigación-enseñanza-extensión), coordinando con otros actores de las Facultades involucradas, así como con otros de la Universidad y de la sociedad en general, en especial, instituciones públicas, movimientos y organizaciones sociales de la zona.

El curso-EFI "Territorio, diseño y comunicación urbana” se configuró entonces como la estrategia principal del Observatorio para el segundo semestre de 2016 y permitió seguir construyendo las líneas de investigación-acción en el marco de Espacios de Formación Integral generados desde las diversas Facultades participantes, lo que asegura la enseñanza y la extensión como funciones siempre presentes en relación con la investigación. Este es un espacio de formación integral en el que se abordan temáticas relativas a los estudios culturales urbanos, con énfasis en el análisis de los procesos de subjetivación, las formas de habitar, el diseño y la comunicación urbana.

Los objetivos planteados para este EFI fueron: 1) que el estudiante transite por una experiencia de involucramiento en un proceso integral de investigación, enseñanza y extensión relativo a la zona Oeste de Montevideo, cargada de significación social y profundidad histórica; 2) que el estudiante incorpore las herramientas de sistematización y análisis de documentos generados en diversos registros semióticos y sus mediaciones, contribuyendo con el Observatorio Socio-Cultural del Oeste de Montevideo en la creación de un repositorio digital comunitario de la zona, en el marco de acciones para la mejora en la calidad de la ciudadanía cultural de sus habitantes; 3) que el estudiante realice diferentes intercambios con movimientos, organizaciones sociales y vecinos de los territorios involucrados, trabajando en forma colaborativa para la consecución de los objetivos anteriormente propuestos. En re- 
lación a la coordinación con las organizaciones de la comunidad que participan del Observatorio Social, se destacan las siguientes: AJUPENFOICA, INAU, Mesa de Coordinación Zonal del Cerro, SOCAT IPRU, Complejo 19 de junio; Parque Tecnológico Industrial y Municipio A.

\section{Herramientas teórico- metodológicas que sustentan las investigaciones del Observatorio}

Se trabaja con metodologías que incorporan herramientas etnográficas, así como el análisis crítico del discurso desde un enfoque sociosemiótico multimodal.

La etnografía contemporánea tiene un carácter experimental, está sustentada en una

experiencia del extrañamiento (inmersión y distanciamiento simultáneos en los fenómenos de estudio) [...] a partir de relaciones intensas, de involucramiento, donde el etnógrafo es el principal instrumento de análisis, al poner en juego y trabajar sobre su propia subjetividad desde todos los aspectos posibles [...] (Álvarez Pedrosian y Blanco Latierro, 2013, p. 1).

La experiencia del extrañamiento se realiza hoy en día en diferentes aspectos de la vida cotidiana de los sujetos, la investigación etnográfica ya no se circunscribe solamente a la inmersión en culturas ajenas o en subculturas urbanas "diferentes" a la cultura hegemónica, en la actualidad cualquier aspecto de la vida cotidiana es posible objeto de investigación.

La antropología y la etnografía contemporáneas hacen cada vez más foco en ese horizonte de desustancialización como forma de acceder a una comprensión más cabal de los fenómenos que estudian, en el permanente movimiento de desmitificación y crítica de las imágenes espontáneas que se construyen sobre tales asuntos. Este es el movimiento básico desde el que opera el extrañamiento como actitud y actividad de des-obviar para acceder a las dinámicas de producción y reproducción de lo existente, actividad cognoscente primordial en la práctica etnográfica (ob. cit., 2013, p. 8).

El fundamento de ello es que en las prácticas culturales que los sujetos realizan en su vida cotidiana se pone en juego un concepto que estructura el pensamiento etnográfico contemporáneo: el habitar.

[...] las formas de habitar, en tanto composiciones de lo existente para ciertas formas de ser (subjetividades) a partir de haceres concretos, prácticas que consisten en des-alejarse y direccionarse en el mundo, no son exteriores al sujeto, sino que lo constituyen, y en tal sentido lo habitan (Álvarez Pedrosian, 2013, p. 5).

En cuanto a las herramientas utilizadas del análisis crítico del discurso, los aportes de la semiótica social permiten describir y comprender cómo las personas producen y comunican significados en contextos sociales diversos. Estos significados se adaptan a las necesidades representacionales y comunicacionales (en diversos modos semióticos) que las personas tienen en su vida social. El paradigma teórico-metodológico en el cual nos posicionamos prioriza la interpretación y la creación de los discursos, en donde los diferentes lenguajes no son una forma de representación de nuestras ideas u objetos, sino un agente de construcción de las realidades sociales. En este marco se desarrollan, particu- 
larmente, las herramientas de análisis de representación discursiva de actores sociales promovidas principalmente por Van Leeuwen (1996).

\section{Desarrollo de las problemáticas y resultados del Observatorio: las particularidades del hábitat social en los territorios del Oeste de Montevideo}

El problema sobre el que se interviene es el de la participación de los habitantes en la construcción de los dispositivos que configuran sus interacciones con el hábitat en los territorios del Oeste de Montevideo. Esta dimensión tiene una fuerte incidencia en la calidad del ejercicio de la ciudadanía de la población. Se considera que una de las vías para promover dicha participación es impulsando dispositivos que posibiliten el acceso, difusión y apropiación del patrimonio simbólico y tangible por parte de la comunidad.

El Observatorio se estructura en ejes de análisis que permitan, por un lado, explicar los procesos de construcción de subjetividad en el territorio y, por otro lado, generar herramientas para transformar los procesos generando una participación mayor de los propios habitantes de los territorios, que se construyen a sí mismos y son construidos por las dimensiones socioculturales que transversalizan al territorio. De esta forma, se realizan reflexiones de los procesos de sistematización e interpretación realizadas, desde el diálogo de saberes, para cada uno de los ejes que componen el Observatorio: la arquitectura, diseño y urbanismo; los medios de comunicación masivos y los medios de comunicación locales.

\section{Fundación, Habitar y Modelo productivo en la Modernidad Sólida}

A finales del siglo xviıI se ordenó la construcción de un Faro en el Cerro de Montevideo a partir de la Real Ordenanza de San Ildefonso, procurando minimizar la pérdida de vidas y bienes causados por los naufragios que en sus cercanías se producían. A los pies de la altura se encuentra "la Casa de la Pólvora" conocida como "El Polvorín", construida en 1794, destinada a guardar la pólvora para la defensa en condiciones óptimas de seguridad. Ambos marcan dos iconos de referencia de un territorio al cual haremos referencia en el transcurso del artículo.

La denominada cosmópolis empieza a habitarse de forma significativa con la llegada de población inmigrante, teniendo como disparador la propuesta que un grupo de industriales, liderados por Samuel Lafone (1805-1871), realizara al Gobierno de Rivera (1784-1854), que era generar las condiciones favorables para atraer la llegada de europeos, fundamentalmente españoles y alemanes, para trabajar en la incipiente industria de los saladeros que abastecía en especial a los mercados esclavistas. Son los primeros indicios que marcaron la influencia del capital con una mirada que excedía los límites territoriales e incorporada a la industrialización de la producción agropecuaria, en este caso, la elección de la mano de obra cuyos cuerpos tuvieran una socialización relacionada a dispositivos de control sobre los mismos, panópticos, y una contracción al trabajo diferente al autóctono. Incide sobremanera en el último cuarto de siglo xix el papel que jugaron los ingleses, cuya industria en origen trabajaba el acero y debía colocar su producción extramuros, introduciendo el ferrocarril, el telégrafo, el teléfono, 
el alambre que fue utilizado en el marcado de la propiedad privada en el medio rural, profundizando las condiciones de dependencia y desigualdad, generando un crecimiento y mejoramiento de los ganados que, como manifestaban Barrán y Nahúm en el texto de Enrique Méndez, "[...] el país del alambrado y de la paz política, objetivos perseguidos desde el Gobierno de Latorre, era incompatible con el país del tasajo" (Méndez, 2011, p. 26). Tal fue la importancia de los saladeros en el procesamiento y exportación de carne, que hubo que esperar hasta 1913 para que la exportación de carne congelada superara al tasajo, producto por un lado de la caída de los mercados esclavistas principales compradores de la carne salada y, por otro, de la necesidad de colocar a mejores precios la carne procedente de ganados mejorados, pensados para ser dirigidos a mercados que brindaran una mejor rentabilidad, y sin duda la aparición de la primera planta frigorífica en el país. "La frigorífica uruguaya", fundada en 1904 con el aporte de capitales ingleses y argentinos, fue ubicada en las instalaciones del viejo saladero Cibils, en la zona oeste de Montevideo. Vestigios de esa estructura productiva quedan en Santa Catalina donde aún se pueden encontrar los restos de viejos saladeros, visitados por el grupo de estudiantes que realizó los trabajos en la zona. A partir de 1912 se instalarán en la zona el Frigorífico Montevideo, luego Swift, un año después abre sus puertas el Frigorífico Artigas, edificación en la cual hoy se encuentra el PTIC y el Ápex. En 1928 se instala el Frigorífico Nacional, al que se le otorga el monopolio del abasto de Montevideo. Los capitales extranjeros estuvieron hasta pocos años después de finalizada la guerra de Corea y en 1957 se retiran. Al año siguiente se crea por ley el complejo de Efcsa que absorbió, bajo la forma de cooperativa entre sus funcionarios, a ambas plantas y cuando transcurría 1978, el Gobierno dictatorial decretó el cese del Frigorífico Nacional, liberalizando el comercio de carnes en todo el territorio nacional, retirándose el Estado de su función de regulador de los precios.

Una de las vertientes de interés, justamente desde la sociología rural, pertenece a este proceso, que demuestra la incorporación de diversos actores a las cadenas agroindustriales, con sus intereses particulares, conflictos, negociaciones, alianzas transitorias, etc., ya pensando en sistemas alimentarios globalizados. Según Bauman (2002) se instauró durante la denominada modernidad sólida un acuerdo, explícito o no, de aceptación de una forma de producción en masa, con jerarquía de funciones y una creciente homogeneización de la fuerza de trabajo. El Estado debía cumplir su papel regulador garantizando la protección social, compensando de esa manera las deficiencias que se pudieran derivar del funcionamiento de la economía. Dispositivos de control según Foucault (2006), que pueden estar dados por las formas de reclusión duras como pueden ser la fábrica, las organizaciones sociales a las cuales el individuo pertenece y sus normativas, los centros educativos como reproductores del modelo dominante, los medios de comunicación como transmisores de una ideología funcional al capital, y por formas de reclusión blandas que se encuentran construidas por el barrio que se encuentra alrededor de los centros productivos, reforzando los lazos con el centro productivo, la direccionalidad hacia el ahorro y las cooperativas de asistencia, colaborando a que no se produzcan descalabros en épocas de crisis del sistema.

Según relatos de informantes relevados por los estudiantes, era muy frecuente que los habitantes de la zona vivieran toda su existencia sin cruzar el Pantanoso. El territorio les brindaba todo aquello que creían 
necesitar: trabajo, educación, recreación, eventos sociales y culturales, deportivos, adquisiciones, etc. Podemos destacar, además de lo ya mencionado en el ámbito laboral, al Teatro Florencio Sánchez, el Mercadito Municipal, las sedes de los tradicionales clubes Cerro y Rampla Jr., la denominada plaza de los Inmigrantes, el excine Cosmópolis, el bar de los Carboneros, la propia casa que hoy alberga a la sede del Ajupen Foica, cargada en su fachada de simbología masónica, entre otros. Esto contribuía a generar una identidad muy fuerte entre los vecinos. Esa suerte de encierro territorial generó también estereotipos creados desde dentro y fuera de la zona. Ese no conocimiento del otro, las luchas reivindicativas de los trabajadores y el papel de los medios de comunicación de la época generaron una estigmatización sobre el lugar y sus habitantes. El cierre de la industria relacionada con el mercado cárnico obligó a los habitantes de la zona a salir en búsqueda de otras ofertas laborales.

Según Berger y Luckman (1986), la realidad se construye socialmente y las acumulaciones específicas de "realidad" y "conocimiento" pertenecen a contextos sociales específicos. El territorio es una construcción en permanente cambio, creado y recreado por sus integrantes. Estas afirmaciones las podemos ver reflejadas en las expresiones de vecinos de las diversas zonas entrevistados por los estudiantes, como en los discursos de los dirigentes de AJUPEN-FOICA, antiguos trabajadores de la industria cárnica que, como hemos mencionado, marcó no solo una época en el Cerro, sino que condicionó el pensamiento y discurso de sus habitantes. Los mismos autores continúan afirmando que

el mundo de la vida cotidiana, no solo se da establecido como realidad por los miembros ordinarios de la sociedad, en el comportamiento subjetivamente significativo de sus vidas. Es un mundo que se origina en sus pensamientos y acciones, y que está sustentado como real por estos" (ob. cit., 1986, p. 37).

Cuando aparecían los relatos sobre los dos kilos de carne que se les daba a cada operario al salir del frigorífico, y de la lucha que se dio cuando esta se quiso cambiar por efectivo, nos marca claramente el valor simbólico que para esta comunidad de trabajadores tenía el producto de su trabajo, no transable por ninguna otra mercancía que pudiera tener el mismo valor de mercado, pero no el mismo significado intrínseco. La propia apropiación de espacios públicos se ve reflejada en algunas locaciones que hoy no están cumpliendo con las mismas funciones que cuando la industria cárnica funcionaba en la zona, pero que nos permite visualizar no solo lugares donde socializaban los parroquianos, como bares asentados en las esquinas, conviviendo más de uno por cuadra, sino que también nos transmiten cómo se distribuían las tareas en el ámbito doméstico.

Uno de los informantes de Santa Catalina, Odorico Velázquez, habla sobre las esquinas en la actualidad como representación del espacio público, lugar que queda como resabio de una época en donde no existía el actual individualismo exacerbado y lo que predominaba era el sentimiento de pertenencia al colectivo.

Relatos de vecinos, y de los mismos dirigentes de la Foica, nos recreaban algunos de los "códigos" internalizados por los propios comerciantes, como, por ejemplo, que en el llamado "boliche de los carboneros", en referencia a quienes trabajaban con ese insumo, cuando las condiciones de confrontación de clases se exacerbaba, es decir, cuando los conflictos se producían en las relaciones obrero-patronales de la indus- 
tria cárnica, ellos adoptaban como conducta el no vender a aquellos que no adoptaran la medida del paro. Eso, si bien les producía una pérdida momentánea al no vender a aquellos que disponían de efectivo, les garantizaba que cuando el conflicto se solucionara, volverían nuevamente a trabajar con todos aquellos obreros combativos hacia los cuales habían manifestado también su actitud de solidaridad en la lucha.

\section{La modernidad líquida, extraños llamando a la puerta y la permanencia del estigma}

Bauman nos hace referencia a que, con la llegada de la denominada modernidad líquida, "las identidades son semejantes a una costra volcánica que se endurece, vuelve a fundirse y cambia constantemente de forma" (ob. cit., 2002, p. 70). Resulta impostergable hacerse de una identidad flexible y versátil para poder sobrellevar las diferentes mutaciones que el sujeto debe enfrentar a lo largo de su vida. El cierre de las grandes fuentes de trabajo directa e indirectamente relacionadas con la industria cárnica, la necesidad de traspasar los límites territoriales en búsqueda de nuevas oportunidades laborales, la llegada durante la década de los ochenta y noventa de poblaciones provenientes fundamentalmente de otras zonas de Montevideo, pusieron a prueba el mantenimiento de una identidad fuertemente arraigada y profundizada a través de casi un siglo. Mientras en la denominada Villa del Cerro las construcciones presentan una cierta homogeneidad entre lo público y lo privado, la extensión del territorio habitado en los nuevos espacios como Santa Catalina, Casabó, Pajas Blancas, La Boyada, Cerro Norte, por nombrar los más significativos, marca una clara diferencia entre las construcciones de los habitantes y las nuevas construcciones, por ejemplo, de locales educativos, policlínicas, etc. Se produce una nueva confrontación simbólica desde lo territorial, lo material y lo social a través de los mecanismos de socialización y sus resultados desde lo cultural.

La apropiación de nuevos espacios y la llegada de nuevas identidades construidas fuera de las generadas a través de décadas en el territorio ponen el imaginario colectivo en alerta, presagiando al decir de Bauman "el desmoronamiento y la desaparición del modo de vida que se conocía, se practicaba y apreciaba" (ob. cit., 2002, p. 50). Según el mismo autor, se produce algo parecido a un "temor extendido entre un gran número de personas que tienen la sensación de que un mal amenaza el bienestar de esa comunidad". La nueva vigilancia líquida (drones, cámaras, helicópteros con la última tecnología) complementa y apoya a los tradicionales aparatos represivos del Estado (ya abordados detenidamente en su momento por Louis Althusser, 1918-1990), al controlar una zona en permanente conflicto, que constantemente se constituye en noticia que vende para los medios masivos de comunicación. Pierre Bourdieu (1997) en su texto "Acerca de la televisión" maneja el concepto de ocultar-mostrando, y en ese proceso muestro lo que me da rentabilidad, lo que sorprende al televidente, ocultando las verdaderas razones del porqué eso se produce. Resulta relevante destacar el señalamiento de Manuel Castells, "el poder se ejerce mediante la coacción (o la posibilidad de ejercerla) y/o mediante la construcción de significado, partiendo de los discursos a través de los cuales los actores sociales guían sus acciones" (Castells, 2009, p. 33). Esto construye una nueva conceptualización de un territorio ya estigmatizado.

Si en la denominada modernidad sólida el estigma estaba fuertemente construido y dirigido a descalificar a un territorio fuertemente combati- 
vo con un soporte ideológico crítico, y contestatario al poder dominante y sus principios, en la modernidad líquida en donde las nuevas condiciones han deteriorado la construcción del concepto del "obrero colectivo", que se daba fuertemente en los establecimientos con presencia fuerte de trabajadores, se profundiza el individualismo y la caída del interés por temas sociales, el estigma es construido a partir de otra faceta que contraviene al "buen vivir y las buenas costumbres sociales", como es la permanente aparición en la escena pública de la asociación de los nombres de los territorios de la zona en relación con el delito. Construcciones de los denominados "Palomares" en Cerro Norte y la permanente presencia de los aparatos represivos del Estado armados como para la guerra marcan un escenario en donde la confrontación y la violencia forman parte de la socialización desde las primeras etapas de la vida de un habitante.

El concepto de exclusión parecería ser, por diversos motivos, una constante de este territorio de la capital, que aglutina a un contingente de ciudadanos muy significativo y donde viven un número importante de niños a los que hay que apoyar en procesos de inclusión y no a la inversa.

\section{Las evidencias discursivas en el análisis de los medios masivos sobre los territorios del Cerro}

Con relación a las representaciones mediáticas del territorio, surgen algunas dimensiones discursivas que se considera que tienen una fuerte incidencia en la vida cotidiana de los habitantes. Los medios de comunicación construyen espacios colectivos simbólicos, que representan las realidades territoriales a partir de ciertas connotaciones, que definen fuertemente los vínculos de convivencia entre los habitantes y los significados del cotidiano vivir en el territorio. Veamos ahora algunos mecanismos utilizados por los medios masivos de comunicación para generar el efecto de lo que definiremos como un "territorio excluido", así como la asociación a los conceptos de violencia, inseguridad y lo que definiremos como "territorio en guerra".

\section{Los tópicos más recurrentes}

Se obtuvieron noticias de 29 distintos medios. Todas fueron compiladas por los estudiantes y estos las consiguieron a partir de sus portales en Internet. Los medios con los que se trabajó fueron: Portal 180, portal del APEX, Cuadernos de taller, El diario, El Espectador, El observador, El País, El Pueblo, portal de la Intendencia de Montevideo, portal del Ministerio de Transporte y Obras Públicas, portal del Municipio A, Noticias Sol, portal del Parlamento del Uruguay, Pica TV, portal del PITCNT, prensa del oeste, portal de Presidencia del Uruguay, Portal del Polo Industrial Tecnológico del Cerro, revista Uruguay, Subrayado, Teledoce, Telenoche, Tenfield y Todo Mountain Bike.

Después de leer todas las noticias se eligieron 12 conceptos, los cuales se presentan a continuación, para poder categorizarlos. Estos pretenden clasificar a grandes rasgos las noticias, lo que no significa que no se hayan podido usar otras, pero las elegidas fueron las noticias sobre:

- Cultura, cuando la noticia hace referencia a algo cultural, como el carnaval;

- Deporte, cuando la noticia hace referencia a algo deportivo, así sea a los cuadros de tradición barrial arraigada en el Cerro, como 
las distintas actividades que se pueden dar en las plazas del territorio referido;

- Economía, cuando la noticia hace referencia tanto a alguna actividad económica que se practica en el territorio, como cuando alguna decisión que es tomada por otros agentes, pudiendo ser el Ministerio de Economía y Finanzas, u otros, tendrán alguna repercusión en el Cerro;

- Espacios públicos se utiliza cuando la noticia que se comunica está relacionada con los espacios públicos que tiene el territorio, haciendo referencia al espacio público como aquel espacio de propiedad pública, dominio y uso público;

- Una noticia es de carácter informativa cuando no tiene otro fin más que el de comunicar e informar algo que sucedió o va a suceder. Si bien todas las noticias son, o deberían ser, informativas, muchas veces se le da más relevancia al hecho sobre el cual se desea informar. Y por lo tanto se decidió categorizar en otro grupo;

- Una noticia es política cuando hace referencia a algo político, en este caso hablamos siempre de decisiones o comentarios que han tomado agentes del Gobierno y de la oposición, ya sea departamental o nacional, en el territorio durante el período estudiado;

- La noticia es categorizada como una noticia sobre salud cuando hace referencia a un centro de salud que hay en el territorio, o sobre alguna política pública sobre salud que se está llevando o se llevará a cabo en el territorio;

- Seguridad, cuando la seguridad ciudadana y el orden ciudadano se ve alterado, ya sea por violaciones de la propiedad privada, derechos humanos u otro tipo de vulnerabilidades que pueden suceder;

- Las noticias que fueron categorizadas como noticias de tránsito son noticias en donde se hace mención al tránsito capitalino, ya sea por un accidente ocasionado o porque de alguna manera el tránsito se ve afectado, por un corte de ruta en el territorio, o lo que fuere;

- Turismo, cuando la noticia hace referencia al turismo que recibe, o cómo se prepara para recibirlo el territorio.

De las 187 noticias seleccionadas podemos decir que, mediante la forma de categorización ya descrita, más de la mitad, el 52\%, hablan de seguridad, que, en primera instancia, es lo que se puede sospechar, dada la estigmatización que existe en este barrio.

La categoría que le sigue es la de educación, con un 18\%, después la de espacios públicos $15 \%$, cultura $5 \%$, deporte $4 \%$, salud $3 \%$, economía, turismo e información representan el $1 \%$ y política y tránsito no llegan ni al $1 \%$.

Se realizará un análisis discursivo multimodal en relación principalmente al tipo de noticias pertenecientes al 52\% de las noticias seleccionadas, es decir, las categorizadas como noticias sobre seguridad.

Las formas de representación mediática de los territorios y sus habitantes

En primera instancia es relevante señalar algunas consideraciones en relación al marco teórico-metodológico que permite establecer los instrumentos de análisis de los discursos mediáticos sobre este territorio. Van Leeuwen (2005), autor reconocido en el abordaje teóri- 
co del análisis de discursos desde una perspectiva socio-semiótica y multimodal, destaca que en el texto podemos encontrar la representación de una o varias prácticas sociales dependiendo de la legitimación o des-legitimación que los enunciadores otorguen a estas, en función de sus intereses. Todas las prácticas sociales involucran a un grupo de actores sociales, pero en una representación dada no todos los actores sociales son incluidos. Unos son representados expresamente y otros son excluidos o sugeridos de manera tácita. Las representaciones incluyen o excluyen actores sociales para ajustarse a sus propósitos e intereses en relación con los lectores a quienes van dirigidos. Muchos de ellos se ajustan a intereses de representar positiva o negativamente, de minimizar o maximizar los hechos, las personas, los objetos, etc.

Algunas exclusiones no dejan rastro en la representación, excluyendo tanto a los actores sociales como a sus actividades. Tal exclusión radical puede jugar un papel en una comparación crítica de diferentes representaciones de la misma práctica social, pero no en el análisis de un solo texto, por el simple hecho de que no deja rastro, cuando las actividades son incluidas, pero alguno o todos los actores sociales involucrados son excluidos, la exclusión si deja rastro (Van Leeuwen, 1996, p. 36).

En los análisis realizados al corpus de medios masivos nacionales en el período de 2016 encontramos que se incluyen actividades en el territorio, pero se excluye a algunos actores sociales como a los propios habitantes, y de alguna forma queda minimizada la vida cotidiana de los habitantes de los territorios en el Cerro de Montevideo. Hay que distinguir, tomando como referencia el mismo autor, entre una "supresión" y una "puesta en segundo término". Para el caso de la supresión, no hay referencias a los actores sociales excluidos, en la exclusión por "segundo término" generalmente los actores no son mencionados en relación a la actividad principal, pero sí son representados marginalmente y podemos detectar quiénes son.

Es precisamente este mecanismo de poner en "segundo término" a los habitantes de estos territorios el que encontramos con mayor recurrencia en los textos multimodales analizados. Vemos, por ejemplo, que en muchas imágenes los habitantes son representados fuera de foco, o en un tamaño menor, perdidos en un plano general, o fuera de campo. Se trata de una exclusión en una "puesta en segundo plano", están allí, se los puede identificar, pero no protagonizan las acciones principales. La construcción mediática de los territorios del Cerro y adyacentes tiene por lo general a los habitantes excluidos entonces por "puesta en segundo plano" de las configuraciones principales con las que son representados dichos territorios: procesos delictivos, enfrentamientos, conflictos, narrativas bélicas.

Las representaciones pueden atribuir a los actores sociales roles activos o pasivos. La "activación" ocurre cuando el actor social es representado como fuerza activa, dinámica, de una actividad, la "pasivización", cuando son presentados como los que sufren la actividad o como los que al final la reciben (Van Leeuwen, 1996, p. 38).

En este sentido, aparecen representados "activamente" actores como "policías", "tecnologías", "espacios geográficos" y "pasivamente" a los habitantes. Veamos algunos ejemplos: 
Si ponemos la mirada sobre el participante representado como "territorio", interesa conocer cuáles son las categorías analíticas que componen en los medios ese concepto de territorio. Hay un componente geográfico, que representa el territorio y se expresa en una serie de imágenes que ilustran titulares que nombran a los territorios. Generalmente la imagen geográfica se representa a partir de un plano general el cual a su vez genera un significado despersonalizado, alejado de la mirada del lector.

Las imágenes y titulares de las noticias contenidas en las Figuras 1, 2, 3 y 4 son ilustrativas de la exclusión o la puesta en segundo término de los habitantes y la activación de otros actores asociados al concepto de guerra tales como: "armas", "policías", "geografías con signos de destrucción", "abandono".

\section{Liceo de Casabó: una institución amurallada}

Tras siete años de reclamo y luego de varias agresiones a docentes, construyeron el muro del 50 .

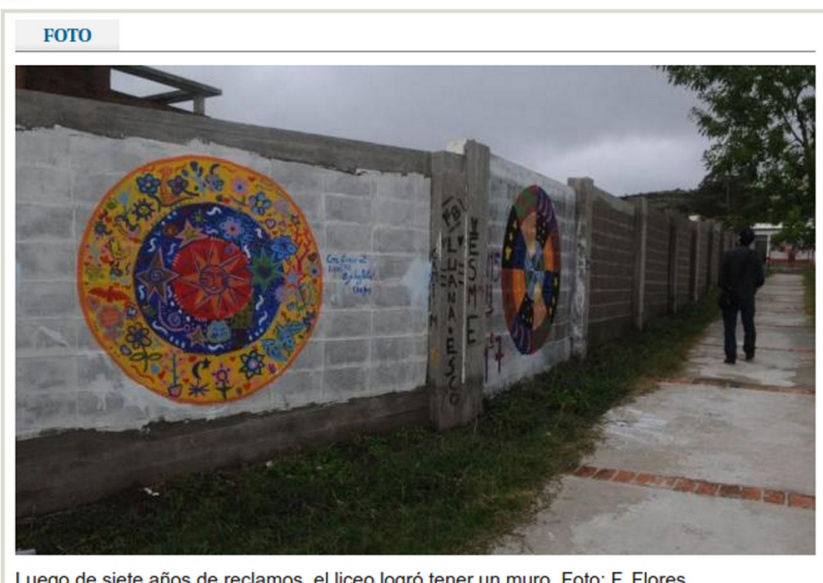

EL DELITO EN BARRIOS HUMILDES

\section{Alerta por escalada en Casabó}

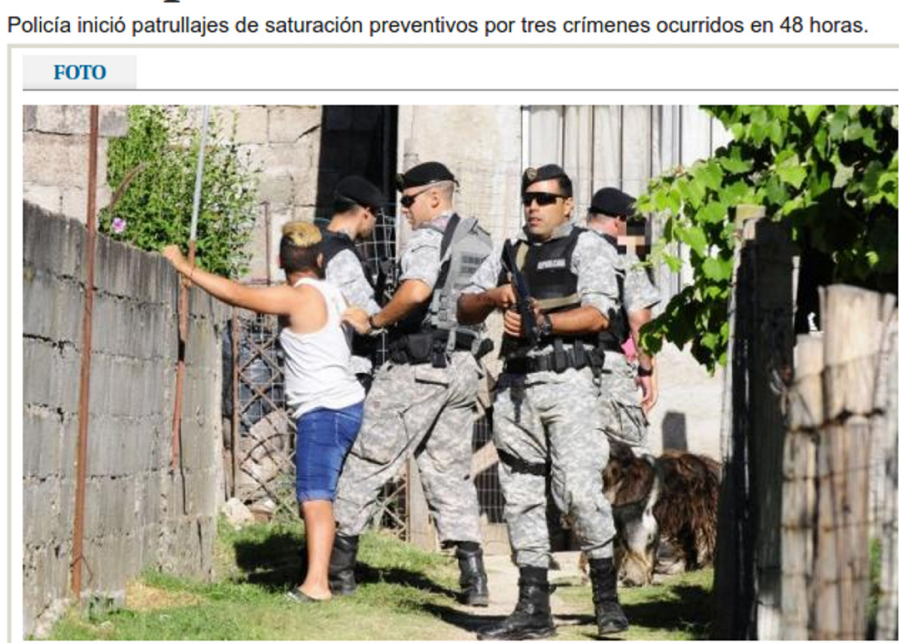

Efectivos de la Republicana persiguieron a un sujeto que quiso esconderse. Foto: D. Borrell
VEA LA FOTOGALERIA

\section{Sitian, disparan y apedrean el destacamento de Santa Catalina}

Otra vez en el barrio Santa Catalina hubo enfrentamientos entre la Policía y vecinos. Molestos por la detención de dos adolescentes, una treintena de jóvenes rodeó la subcomisaria del barrio donde se parapetaron ocho efectivos policiales.

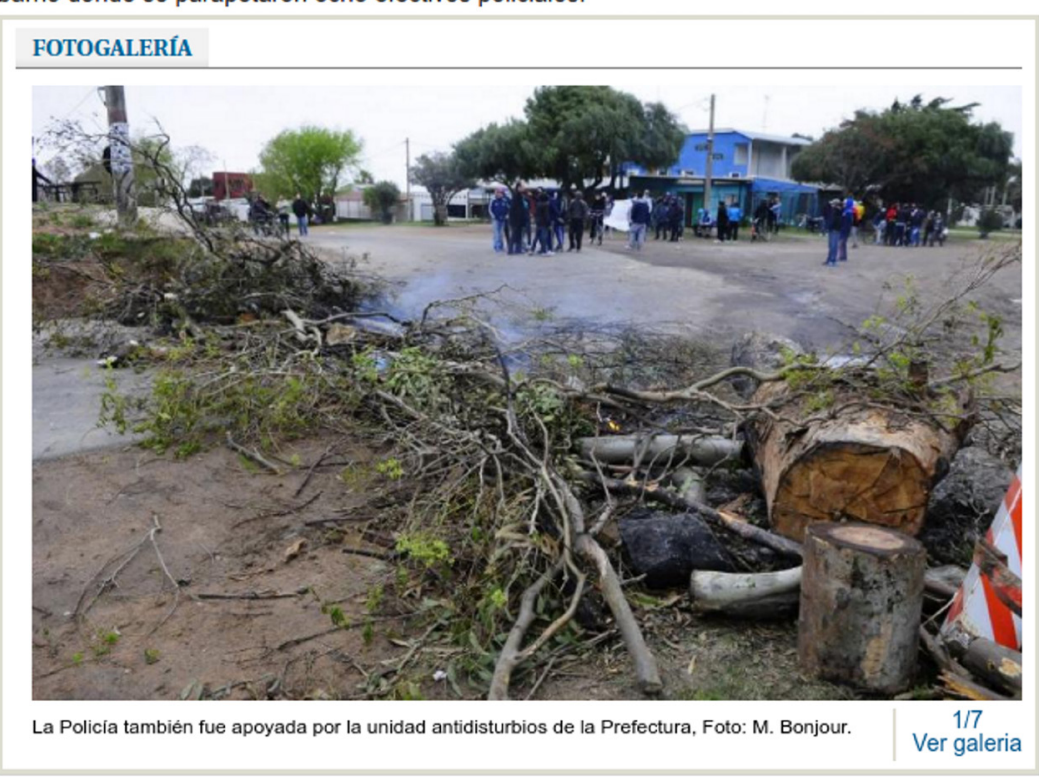

Figura 1. Captura de pantalla de artículo de prensa. Fuente: Liceo de Casabó, una institución amurallada (21 de marzo de 2016)

Figura 2. Captura de pantalla de artículo de prensa. Fuente: Alerta por escalada en Casabó (3 de febrero de 2016$)^{3}{ }^{3}$ Figura 3. Captura de pantalla de artículo de prensa. Sitian, disparan y apedrean el destacamento de Santa Catali$n a^{4}$ (23 de setiembre de 2015)

3 Alerta por escalada en Casabó (3 de febrero de 2016). El País. Recuperado el 25 de abril de 2017 de: http://www.elpais. com.uy/informacion/autoridades-alertan-escalada-violencia-casabo.html. 4 Sitian, disparan y apedrean el destacamento de Santa Catalina (23 de setiembre de 2015). El País. Recuperado el 25 de abril de 2017 de: http://www.elpais. com.uy/informacion/sitian-disparan-apedrean-destacamento-santa.html). 
Los actores sociales pueden ser referidos como individuos, en cuyo caso se habla de individualización; o como grupo, que se denomina asimilación. Dado el gran valor que se le otorga a la individualidad en ciertas esferas de nuestra sociedad, estas categorías deberían de ser de primer orden en el análisis crítico del discurso (Van Leeuwen, 1996, p. 39).

La exclusión o disminución de los habitantes de estos territorios ayuda a construir un significado social del Cerro de Montevideo y sus adyacentes como zonas inseguras, despobladas, "territorios de nadie". Es un significado similar al generado cuando se plantean este tipo de representaciones con relación a una guerra lejana, en donde no aparecen las actividades cotidianas de las personas, sino la destrucción y la no-vida cotidiana. Se propicia una presentación de los habitantes y de los fenómenos en el territorio que se despersonalizan, ayudan a construir la idea de una zona anónima, sin particularidades, presentada en términos generales. Esta forma discursiva aporta a los procesos de segregación territorial y de los habitantes como un grupo, sin rasgos individuales. Se colectiviza cuando se habla de este barrio, esta zona, este territorio. Se utilizan sustantivos colectivos o nombres que denotan a un grupo de personas u objetos.

Ejemplo de esto, son los fragmentos de texto capturados donde se enuncia:

[...] habitantes del Cerro quisieron cortar la calle como objetivo de protesta, ya que metieron presos a dos jóvenes que allí habitaban. Estos jóvenes fueron procesados con prisión, puesto que asesinaron a un joven de 19 años. 150 policías en operativo ${ }^{5}$ o Los vecinos oyeron tres disparos, y luego vieron a tres sujetos desconocidos alejarse del lugar $[\ldots] .^{6}$

Los habitantes están incluidos en la representación, pero aparecen despersonalizados a través del recurso de la colectivización: "habitantes del Cerro", "los vecinos", etc., dejan en primer plano los sucesos violentos representados.

La indeterminación ocurre cuando un actor social es representado como in-específico, individuos o grupos anónimos; la determinación, cuando su identidad es de una manera u otra, especificada. La indeterminación es lograda típicamente por los pronombres indefinidos (alguien, algo, algún, algunas personas), usados en función nominal, alguien puso flores en el escritorio del profesor. Aquí la indeterminación deja anónimo al actor social (Van Leeuwen, 1996, p. 40).

Los actores sociales pueden ser representados tanto en términos de su identidad única, siendo nombrados — nominados-, o en términos de identidades y funciones que comparten con otros (categorización), y es, otra vez, interesante investigar cuáles actores sociales son categorizados y cuáles nominados (ob. cit., 1996, p. 41).

5150 policías en operativo para impedir corte de ruta en el Cerro (17 de diciembre de 2015). Montevideo Portal. Recuperado el 25 de abril de 2017 de: www. montevideo.com.uy/auc.aspx?293991.

6 Hombre de 56 años muere al ser baleado en su casa del Cerro (3 de febrero de 2016). Montevideo Portal. Recuperado el 25 de abril de 2017 de: http:/ / www. montevideo.com.uy/auc.aspx?298474.
Los actores nominados tienen un mayor protagonismo en la construcción de los significados, mientras que los que no lo son quedan en un segundo orden, siendo agentes con mayor pasividad; se construye una representación que presenta las interacciones sociales dando un destaque a ciertos actores sobre otros, los que tienen nombre.

[...] en Haití y Vizcaya, en pleno corazón de Cerro Norte, un niño de unos cinco años insultaba a la policía que minutos antes había realizado 
un operativo de control de motos a 20 metros de distancia. Otros vecinos comenzaron a salir de sus casas y mirar amenazadoramente a los policías, quienes armaron una formación "en estrella" para poder cubrir todos sus flancos. Contra la pared de un muro, dos individuos que circulaban sin casco en una moto desvencijada eran cacheados. Un policía solicitó a uno de ellos que abriera su mochila. Mientras que un oficial, con las cédulas de los dos jóvenes en de sus manos, hablaba por un handy para saber si estos estaban requeridos o no. Cinco minutos más tarde, el conductor de la moto y su acompañante fueron autorizados a continuar el viaje porque todo estaba en orden. ${ }^{7}$

Michel Foucault (2002) desarrolló en Vigilar y Castigar el concepto de "peligrosidad" que supone que el individuo es potencialmente capaz de infringir un delito, la norma lo debe prever, aunque no necesariamente todos lo lleguen a cometer. La noticia anterior y el control recrea este concepto, ya que los individuos, luego de ser detenidos y analizados, al no estar requeridos por delito alguno, pueden seguir su camino. Eran potencialmente sospechosos de estar en falta, no se les encontró nada, por lo cual "siguen en libertad".

Este ejemplo muestra cómo los habitantes que van interactuando en esta situación son categorizados por sus rasgos etarios (un niño, jóvenes) o por ser "vecinos" o por la indeterminación, "los individuos", o por su función, "policías" o "conductores de moto". Lo que aparece nombrado son las calles donde ocurre y el nombre del barrio, "Haití y Vizcaya" y "Cerro Norte". Es decir, que vemos que nuevamente se disminuye el protagonismo de las personas, particularmente de los habitantes, y se activa el rol protagónico del lugar, de la zona, el componente geográfico del territorio, que en este caso es nominado. Esto refuerza la idea de lo des-humanizado, de zona ajena, excluida y estigmatizada.

Otra forma recurrente de representar a los habitantes en el territorio es a través del mecanismo de "objetivación". Son representados por medio de referencias a un lugar o cosa relacionada espacialmente, hay aquí referencia metonímica. Esta objetivación construye un significado de impersonalización compatible con el estudio de las imágenes en donde protagoniza el espacio y la figura humana queda alejada.

Como conclusiones preliminares sobre esta línea de trabajo encontramos entonces una construcción mediática, del territorio del Cerro de Montevideo y sus adyacentes, que establece un discurso bélico, de zonas de guerra en la que el mecanismo utilizado para apoyar este discurso es disminuyendo o excluyendo a los habitantes de sus actividades cotidianas en el territorio, mientras que se activan algunas representaciones sociales que apoyan conceptualmente este discurso: geografías despobladas, incidentes de violencia que ocurren en el territorio, uso de imágenes de elementos de guerra como armas, balas, ejércitos, fuego, textos que explícitamente utilizan conceptos bélicos como "guerra", "combate", "zona roja", etc. Estas representaciones mediáticas del territorio también son el territorio, por esa idea hermenéutica-constructivista de que los lenguajes no reflejan la realidad, sino que la construyen, influyen directamente en la construcción mental que los habitantes hacen de sus propios territorios, de las problemáticas que los definen, de las valoraciones de los "otros", del "nosotros". Tienen una fuerte incidencia en las otras dimensiones que hacen de la constitución territorial, la planificación urbana de espacios públicos, por ejemplo, queda directamente relacionada con los imaginarios territoriales
7 Alerta por escalada en Casabó (3 de febrero de 2016). El País. Recuperado el 25 de abril de 2017 de: http:/ /www.elpais. com.uy/informacion/autoridades-alertan-escalada-violencia-casabo.html. 


\begin{tabular}{llllllllll|l|l|l}
\hline EL OBSERVADOR & SECCIONES & CROMO & REFERI & AGRO & PADRES HOY & OTV & BLOGS & MAS & SERVICIOS & $\mathbf{2}$ & $\boldsymbol{T}$ & $\mathbf{Q}$ \\
\hline
\end{tabular}

NACIONAL POLICIALES

\section{Guerra de bandas criminales: Casabó vs Santa Catalina}

Octubre $30,201511: 06$

() TIEMPO DE LECTURA: 2 MINUTOS

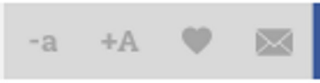

f $315 \quad y+$

Un joven fue abatido cuando uno de los grupos buscaba vengarse por la muerte de uno de sus integrantes

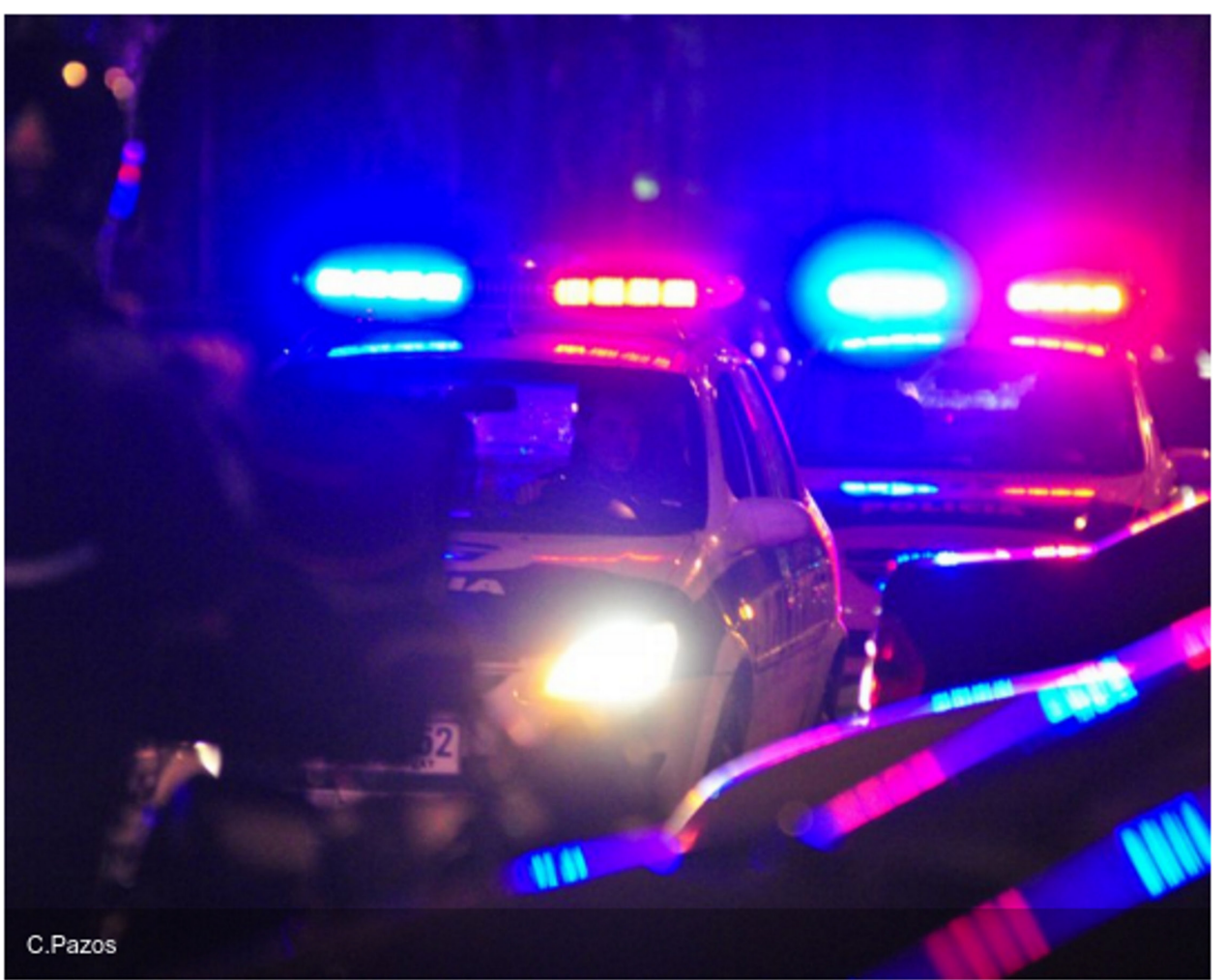

Las más leidas

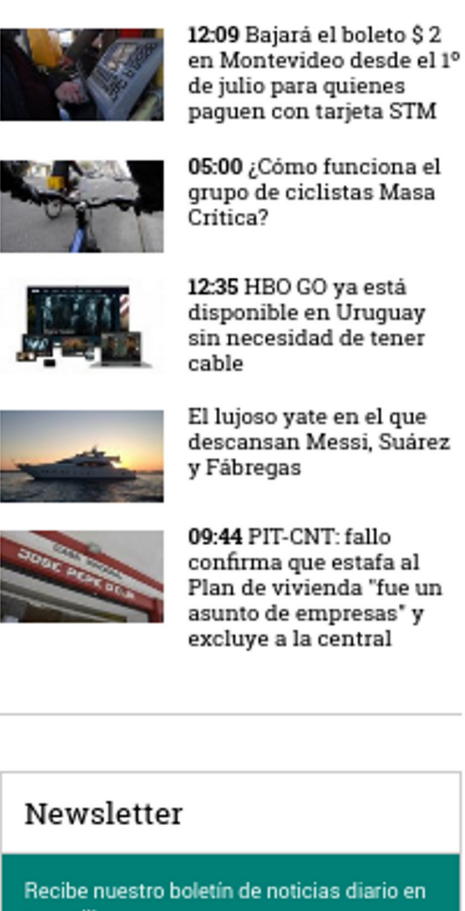

Figura 4. Captura de pantalla de artículo de prensa. Fuente: Guerra de bandas criminales. ${ }^{8}$
8 Guerra de bandas criminales: Casabó vs Santa Catalina (30 de octubre de 2015). El Observador. Recuperado el 25 de abril de 2017 de: http:/ / www.elobservador.com.uy/guerra-bandas-criminales-casabo-vs-santa-catalina-n688957. que en gran medida se sustentan en estas representaciones simbólicas generadas desde un "afuera" del territorio a través de los medios masivos de comunicación social.

No es de extrañar que, por ejemplo, las problemáticas planteadas por los propios habitantes que luego determinan soluciones habitacionales, de configuración de los espacios públicos, estén fuertemente influenciadas por las representaciones simbólicas que no solo definen la agenda de tópicos, sino las valoraciones sobre los mismos. Esas tensiones están constantemente en juego cuando se producen los intercambios entre los habitantes, los contrastes entre lo simbólico mediático, lo simbólico cotidiano, lo tangible, etc. Muchos de esos contrastes se pueden detectar en el análisis de los discursos generados en la prensa local, que necesariamente busca generar contrapesos a estas representaciones mediáticas masivas.

\section{Conclusiones}

Las principales conclusiones elaboradas a partir del análisis de los diferentes ejes detectan procesos de "exclusión" de este territorio y de sus habitantes, los mismos se visualizan tanto en las representaciones sim- 
bólicas mediáticas como en los dispositivos presentes en espacios públicos y en la planificación urbana.

Es sustancial, a nuestro entender, que la universidad, en el marco de sus funciones, propicie acciones que faciliten la "inclusión" de los que están siendo excluidos por los poderes hegemónicos. Este tipo de plataformas permiten visualizar los mecanismos de exclusión y las formas en que los dispositivos establecen relaciones de poder, las formas en que activan o des-activan a los actores sociales según determinados intereses. La propia incorporación en el Observatorio de los actores sociales involucrados en estos procesos de por sí ya es una acción que propicia la transformación de estas realidades, pero no alcanza con esto. El Observatorio sociocultural, además de incorporar más actores sociales en la mirada crítica de los procesos territoriales, debe buscar nuevos dispositivos para la participación social que se configuren como solución a los problemas emergentes de la interacción de los sujetos con el hábitat. La posibilidad de construir problemáticas de forma crítica entre todos los actores sociales (organizaciones sociales, habitantes, actores académicos, etc.) permite la apuesta por soluciones más adecuadas a los intereses vitales de los propios habitantes y el aporte universitario debe ir en el sentido de construir estas redes-dispositivos de co-diseño social, con el objetivo de la elaboración de problemáticas y de la actualización de soluciones a dichas problemáticas, pero también debe propiciar elementos técnicos que permitan fortalecer poderes contra-hegemónicos que permitan la "inclusión" y la resignificación de los espacios habitables. Conocer y reflexionar sobre los mecanismos de "exclusión" de los territorios y sus habitantes permite trabajar en las propias redes sociales para buscar mecanismos que permitan contrarrestar dichos procesos. 


\section{Referencias}

Álvarez Pedrosian, E. (2013). El Ser habitado: Diseño existencial y procesos de subjetivación. Montevideo: ALTEHA-FArq-UdelaR. Recuperado el 25 de abril de 2017 de: http:/ / eduardoalvarezpedrosian.blogspot. com.uy/2013/06/el-ser-habitado-diseno-existencial-y.html.

Álvarez Pedrosian, E. y Blanco Latierro, M. (2013). Componer, habitar, subjetivar: Aportes para la etnografía del habitar. Bifurcaciones: revista de estudios culturales urbanos-Talca. Recuperado el 25 de abril de 2017 de: http:/ / www.bifurcaciones.cl/bifurcaciones/wpcontent/uploads/2013/12/bifurcaciones_015_Alvarez.pdf.

Bauman, Z. (2002). Modernidad liquida. Buenos Aires: Fondo de Cultura Económica de Argentina S.A.

- (2016). Extraños llamando a la puerta. Barcelona: Espasa Libros S.L.U.
Berger, P. y Luckman, T. (1986). La construcción social de la realidad. Buenos Aires: Amorrortu.

Bourdieu, P (1997). Acerca de la Televisión. Barcelona: Anagrama.

Castells, M. (2009). Comunicación y poder. Madrid: Alianza Editorial.

Foucault, M. (2002). Vigilary Castigar. Buenos Aires: Siglo XXI Editores.

- (2006). Verdad y Formas Jurídicas. Montevideo: Fondo de cultura Universitaria.

Méndez Vives, E. (2011). El Uruguay de la modernización 1876-1904. Montevideo: Banda Oriental.

Van Leeuwen, T. (1996). The representation of social actors. En Caldas-Coulthard, C.R. y Coulthard, M. (eds.), Texts and practices readings in critical discourse analysis. London: Routledge, pp. 32-70.

- (2005). Introducing social semiotics. Londres: Routledge.

Olivetti Espina, M., Castro Falero, J., Lago, G. y Rodríguez, C. (2017). Observatorio Socio-culltural del Oeste de Montevideo: Una plataforma integral universitaria. Hábitat y sociedad, 10, 145162.

<http:/ /dx.doi.org/10.12795/HabitatySociedad.2017.i10.09> 